[v.1, n.1] Jan./Jun.2020

ARTIGO DOI 10.33872/conversaspsico.v1n1.lutoantecipatorio

Recebido em: $15 / 11 / 2020$

Publicado em: 18/06/2021

\title{
LUTO ANTECIPATÓRIO EM PACIENTES COM MICOSE FUNGÓIDE
}

Daniele Batista de Sousa ${ }^{1}$ orcid.org/0000-0002-6962-073X

Marcus Vinicius da Silva Vieira ${ }^{2}$ orcid.org/0000-0002-0040-000X

Júlia Catani ${ }^{3}$ orcid.org/0000-0003-3096-4532

RESUMO. Introdução: A Micose Fungóide (MF) é muito além de uma doença crônica não-transmissível, é uma palavra que define diversas manifestações físicas e psicológicas que afetam o indivíduo tanto direta quanto indiretamente. Objetivo: Investigar as emoções vivenciadas e como se dá a experiência potencial de luto antecipatório ou melancolia para o indivíduo que depara-se com a MF. Métodos: Pesquisa de campo qualitativa descritiva transversal com quatro pessoas entrevistadas individualmente, membros de grupo informal de pacientes com MF. Através de análise do discurso de cada participante foi possível criar três categorias acerca do luto antecipatório, sendo: 1. Fases do Luto, 2. Mecanismos de Defesa e, 3. Câncer como "sentença de morte". Resultados e Discussão: A discussão buscou articular os momentos pelos quais os pacientes estão vivendo as fases do luto de Kubler-Ross. Considerações Finais: A presença das fases do luto ocorreu de forma oscilante na análise do discurso, isto é, foi possível observar mais de uma fase concomitante. No que se refere aos mecanismos de defesa, um movimento semelhante também ocorreu. Ainda que presentes, não foi possível classificá-los de modo específico. Na utilização destes recursos psíquicos constatamos a vivência do luto antecipatório, ou seja um sofrimento por parte dos pacientes diante da constatação do diagnóstico.

Palavras-chave: Luto antecipatório, Micose Fungóide, sofrimento psíquico.

\footnotetext{
${ }^{1}$ Psicóloga pela Universidade São Judas e Residente Multiprofissional no A.C. Camargo Cancer Center; E-mail: sousa.btt@gmail.com

${ }^{2}$ Psicólogo pela Universidade São Judas; E-mail: marcuscontatopessoal@gmail.com.br

${ }^{3}$ Psicóloga e Psicanalista. Membro do Instituto Sedes Sapientiae e do Grupo de Estudos Brasileiro de Sándor Ferenczi. Pós-doutoranda pela Faculdade de Educação da Universidade de São Paulo (USP) com bolsa FAPESP - processo 2019/26703-4. Doutora e Mestre em Psicologia Clínica pela USP.E-mail: juliacatani@usp.br
} 


\title{
ANTICIPATORY MOURNING IN MYCOSIS FUNGOID PATIENTS
}

\begin{abstract}
Introduction: Mycosis fungoides (MF) is much more than a chronic non-communicable disease, it is a word that defines several physical and psychological manifestations that affect the individual both directly and indirectly. Objective: Investigate the emotions experienced and how the potential experience of mourning occurs anticipatory or melancholy for the individual who is faced with MF. Methods: Qualitative research cross-sectional description with four people interviewed individually, members of an informal group of patients with MF. Through the analysis of the speech of each participant, it was possible to create three categories of anticipatory grief, 1. Grief phases, 2. Defense mechanisms and, 3. Cancer as a "death sentence". Results and Discussion: The discussion sought to articulate the moments in which patients are experiencing stages of Kubler-Ross mourning. Final Considerations: The presence of the phases of mourning occurred in an oscillating way in discourse analysis, that is, it was possible to observe more than one concomitant phase. Regarding to defense mechanisms a similar movement has also occurred. Although present, it was not possible classify them in a specific way. In the use of these psychic resources we see the experience of mourning anticipatory, that is, suffering on the part of the patients when the diagnosis is confirmed.
\end{abstract}

Keywords: Anticipatory mourning, Mycosis Fungoid, Defense mechanisms, psychic suffering.

\section{INTRODUÇÃO}

A descoberta de um câncer nunca será fácil, pois, a doença ainda é tratada como sinônimo de iminência de morte. Segundo Torres (1994) a palavra câncer eventualmente implica em si mesma o conceito de morte antecipada, de sofrimento sem esperança, de perda do futuro. Todavia, a medicina oncológica caminha a passos largos e desenvolveu terapêuticas que controlam com eficiência a maior parte dos tipos de câncer. Segundo Dunker (2015), ao discutir o sofrimento nos referimos à oportunidade de fala do paciente, suas expectativas, sua teoria da doença, da cura e sua compreensão dos sintomas.

O presente estudo, advindo de um trabalho de conclusão de curso, investigou a vivência do luto antecipatório em pacientes diagnosticados com um tipo específico de câncer, o linfoma de células T/B (Micose Fungóide). O câncer é muito além de uma doença crônica não-transmissível, é uma palavra que define diversas manifestações físicas e psicológicas que afetam o indivíduo tanto direta quanto indiretamente. 
[v.1, n.1] Jan./Jun.2020

A Micose Fungóide é o subtipo mais comum de LCCT (Linfomas Cutâneos de Células T), representando mais de 50\% dos casos. Sua incidência anual nos Estados Unidos é de 0,36 caso/100.000 habitantes e na Europa com 1 caso/100.000 habitantes (Gaiewski, 2015). No Brasil, até o momento desta investigação, não foi possível encontrar dados sobre a incidência do LCCT . Existem linfomas de células B e T, sendo o primeiro, menos frequente e mais agressivo, LCCT é uma neoplasia maligna resultante da proliferação de células do sistema linfóide. Segundo Nunes (2004), como na Micose Fungóide (MF): “Os linfomas não-Hodgkin constituem um grupo de neoplasias derivadas de clones de linfócitos em seus diferentes estágios evolutivos. Podem originar-se primariamente nos linfonodos (linfomas nodais) ou em tecidos linfóides associados a mucosas, pele ou outras estruturas (linfomas extranodais)". Vale acrescentar que, o linfoma também é classificado em subgrupos, assim sendo: os Linfomas de Hodgkin, que se espalham de forma ordenada de um grupo de linfonodos para outro grupo, e os Linfomas não Hodgkin, que se espalham de maneira não ordenada e podem começar em qualquer lugar do corpo.

O tratamento do linfoma cutâneo é capaz de afetar inteiramente um organismo, na medida em que a admissão endovenosa de quimioterápicos atinge não somente as células cancerígenas, mas também células saudáveis, prejudicando todo 0 funcionamento do corpo do paciente, podendo variar diante de sua especificidade ou grau de comprometimento. Segundo Duarte, Buense, \& Aoki (2006) o tratamento do LCCT ainda é motivo de discussões, sendo propostos diversos métodos terapêuticos para sua abordagem, sem real consenso sobre a melhor alternativa a ser utilizada. Os dados da literatura demonstram que o sucesso do tratamento depende diretamente da fase evolutiva em que se encontra a doença, bem como da resposta individual de cada um. Normalmente, quanto mais precoce a abordagem terapêutica, melhor o prognóstico.

A decisão de estudar o potencial luto em pacientes acometidos por câncer não significa que os mesmos vivenciaram, necessariamente, situações que o colocavam em risco iminente de morte. No entanto, acredita-se que certas circunstâncias, quando experimentadas, também proporcionam à pessoa o sentimento de luto. Este sentimento se dá diante de variadas perdas, sejam essas limitações físicas, abalos emocionais/ psicológicos, prejuízos materiais ou mesmo, inibição de expectativas e planos por circunstâncias específicas advindas da doença. Para Sonoda (2018), o luto é um 
[v.1, n.1] Jan./Jun.2020

processo paradoxal, pois enquanto é um dos maiores desafios ao equilíbrio psíquico, também diz respeito a um processo natural que implica fatores individuais e fatores externos. Sendo o primeiro, a estrutura psíquica do indivíduo, a qualidade do vínculo que foi perdido, as experiências de perdas anteriores, o apoio social percebido, as crenças religiosas que se tem e o preparo que se desenvolve para a perda. $\mathrm{O}$ segundo fator refere-se às circunstâncias da perda e o apoio social que foi recebido.

Nos estudos sobre o luto, Elisabeth Kubler-Ross é muito citada para se compreender o desenvolvimento deste fenômeno em que há caracteristicamente uma perda. "Traduzido para trinta línguas, sua obra foi além da descrição dos cinco estágios (negação, raiva, barganha, depressão e aceitação) pelos quais passam os pacientes diante de uma doença fatal ou que potencialmente ameace a vida" (Afonso \& Minayo, 2013, p. 2730). Segundo Freud (1914/1916), o luto, comumente, é a reação à perda de um ente querido, à perda de alguma abstração que ocupou o lugar deste que faleceu, por exemplo, também são possíveis observações de perdas como: o país, a liberdade ou o ideal de alguém, e assim por diante. É importante destacar que o luto pode ser vivenciado nas diversas situações que possam gerar ameaça à vida. Logo, levando em conta a subjetividade de cada indivíduo, os aspectos que ameaçam sua integridade podem ser diversos e surgem de acordo com os valores, crenças, metas e expectativas.

Para melhor compreendermos o que se passa com os pacientes diagnosticados com MF, propusemos uma análise e aproximação das fases do luto vivenciadas conforme proposto por Kubler-Ross (1926/1998). A primeira fase é classificada de negação, quando a pessoa rejeita o problema, evitando falar sobre o assunto. Geralmente é um tipo de defesa transitória. Posteriormente, a raiva é a fase na qual surgem sentimentos como ira, revolta, inveja e ressentimento (Kubler-Ross, 1926/1998), podendo se manifestar sem um motivo aparente aos demais. Já as barganhas, frequentemente, são feitas com Deus e, psicologicamente, podem se relacionar com algum sentimento de culpa encoberto (Kubler-Ross, 1926/1998). A quarta fase é identificada como depressão. Esta é uma associação de tristeza com outros sentimentos (Susaki et al., 2006). Por fim, a última etapa é a fase de aceitação, não deve ser confundida com sentimento de felicidade, é algo mais próximo à uma fuga de sentimentos, quando a dor se desvanece e o paciente pode sentir-se como que chegando ao fim da batalha (Kubler-Ross, 1926/1998), acatando à sua situação. 
[v.1, n.1] Jan./Jun.2020

Entretanto, é sabido que as pessoas reagem de modo distinto perante as intempéries da vida, mesmo quando vivenciam circunstâncias muito similares, sendo possível encontrar pacientes em luto ou em melancolia (Freud, 1914/1916). E de modo sucinto, podemos diferenciar que "no luto, é o mundo que se torna pobre e vazio; na melancolia, é o próprio ego" (Freud, 1914/1916, p. 251). Isto é, a melancolia se refere à um processo mais intenso, caracterizando-se de acordo com o pai da Psicanálise, em "um desânimo profundamente penoso, a cessação de interesse pelo mundo externo, a perda da capacidade de amar, a inibição de toda e qualquer atividade, e uma diminuição dos sentimentos de autoestima" (p. 250).

O luto em sua forma antecipada surge diante da adversidade da doença, deste modo, ele atinge tanto aspectos emocionais quanto físicos e sociais (Neto \& Lisboa, 2017). Na tentativa de lidar com essa demanda indesejável é esperado que a pessoa desenvolva mecanismos de defesa que a auxiliem no manejo com seus afetos e com a situação de vida enfrentada. Sobre mecanismos de defesa é sabido que, "Sigmund Freud designa por esse termo o conjunto das manifestações de proteção do eu contra as agressões internas (de ordem pulsional) e externas, suscetíveis de constituir fontes de excitação e, por conseguinte, de serem fatores de desprazer" (Roudinesco \& Plon, 1944/1998, p. 141). Já de acordo Zimerman (2008), é a “designação dos distintos tipos de operações mentais que têm por finalidade reduzir as tensões psíquicas internas, ou seja, das angústias. Os mecanismos de defesa processam-se pelo ego e praticamente sempre são inconscientes" (p. 97).

O diagnóstico de uma doença crônica mobiliza diversas defesas que podem auxiliar a pessoa a conviver com aspectos psicológicos não desejados. Ou seja, um diagnóstico crônico, sobretudo no que diz respeito ao câncer, exige um trabalho psíquico árduo para que o paciente tenha condições de enfrentar a sua nova realidade. Através das cinco fases do luto propostas por Kubler-Ross (negação, raiva, barganha, depressão e aceitação) foi possível investigar alguns mecanismos de defesa mobilizados em pacientes com Micose Fungóide, promovendo uma melhor compreensão e percepção do paciente sobre si mesmo e sua relação com os demais, sejam estes profissionais da área da saúde ou pessoas de seu convívio. A hipótese do estudo é de que o recebimento do diagnóstico de câncer, no caso, a MF, mobiliza mecanismos de 
[v.1, n.1] Jan./Jun.2020

defesas similares entre esses pacientes e o resultado deste processo pode desencadear uma espécie de luto antecipatório.

O objetivo do presente estudo foi investigar as emoções vivenciadas e como se dá a experiência potencial de luto antecipatório ou melancolia para o indivíduo que se depara com a descoberta do câncer linfóide de células T/B, mais especificamente a MF.

\section{MÉTODO}

Para tornar possível o desenho do estudo foi realizada uma pesquisa de campo descritiva transversal com abordagem qualitativa. Essa técnica geralmente estuda um número menor de participantes para aprofundar as informações coletadas, utiliza entrevistas semidirigidas ou não diretivas e realiza análise do discurso, de conteúdo, das representações sociais estabelecendo eixos temáticos ou categorias de análise que permitem a tabulação/quantificação das respostas (Gil, 2010).

A investigação foi realizada com quatro indivíduos, com idade acima de 18 anos, diagnosticados/as com Micose Fungóide, membros de um grupo informal de pacientes acometidos pela mesma patologia, em tratamento em São Paulo/SP, que se mantém interligados via redes sociais para troca de informações relacionadas à doença.

Convém assinalar que foi utilizado o Termo de Consentimento Livre e Esclarecido, um Questionário Sociodemográfico para identificação dos participantes e um Questionário de entrevistas semiestruturadas. Este último foi composto por cinco perguntas norteadoras, acerca de como foi receber o diagnóstico, mudanças geradas na rotina, planos e sonhos e autopercepção, além de uma pergunta que motiva o participante a citar momentos marcantes antes e após o diagnóstico. Tal entrevista se propôs a favorecer o reconhecimento dos conteúdos mobilizados no/a paciente e possíveis sinais de luto antecipatório ou melancolia.

A investigação só foi possível de ser concretizada após aprovação do projeto pelo Comitê de Ética correspondente, sabendo-se que esta pesquisa trata-se de um trabalho de conclusão de curso. Foi estabelecido contato com grupos em redes sociais compostos por pessoas acometidas pela patologia, o qual permitiu relação direta e independente com os sujeitos a fim de convidá-los a participar. 
[v.1, n.1] Jan./Jun.2020

Para que as entrevistas pudessem ser realizadas foram agendados encontros individuais com cada participante, em local tranquilo e reservado que favorecia a escuta. Os instrumentos foram preenchidos no início e as entrevistas duraram em média 45 minutos. As entrevistas foram conduzidas pelos pesquisadores em conjunto, e gravadas para posterior transcrição e análise. As gravações, após transcritas, foram descartadas e o material será arquivado por cinco anos e, posteriormente incinerado.

\section{Metodologia da Análise dos Dados}

Para relatar os aspectos significantes provindos de cada entrevista foi utilizada a Análise Qualitativa de Minayo (1994). Dividida em três fases, na primeira, a Fase exploratória, iniciou-se reconhecendo os conceitos fundamentais na operacionalização da pesquisa, o que proporciona a disposição para compreender a experiência vivida pelo outro. Define-se um objeto de estudo, situando-o em um quadro de preocupações teórico-práticas, na área de interesse dos pesquisadores e para o qual haja embasamento bibliográfico suficiente (que seja estudado e cuidadosamente ordenado). De posse deste conhecimento inicial é possível desenvolver as estratégias de campo, definindo quais instrumentos serão necessários para obter os dados pretendidos. Assim pode-se passar para a etapa de exploração do campo, elegendo o espaço e o grupo a ser estudado, os critérios da amostragem e estabelecendo as estratégias de entrada em campo. (Minayo, 1994, 2012).

$\mathrm{Na}$ Fase de trabalho de campo, inicia-se a interação própria da pesquisa qualitativa entre pesquisador e sujeito pesquisado, com a coleta de dados, que é estruturada de acordo com os objetivos e as necessidades da investigação. Por exemplo, pode-se realizar entrevistas (adotando a estrutura mais pertinente) ou observação participante. No presente estudo foi adotada a entrevista semiestruturada favorecendo a expressão do participante a partir de algumas perguntas norteadoras. (Minayo, 1994, 2012).

Na última fase de análise ou tratamento do material, se dá o desafio de examinar o conteúdo obtido. Inferências e interpretações são feitas cuidadosamente usando de técnicas e embasamento na produção científica já existente. Trata-se de um trabalho meticuloso. Ordenar e organizar o material, categorizar o conteúdo coletado, de modo a interpretar com a teoria existente. A interpretação final tem como pretensão, a partir da 
[v.1, n.1] Jan./Jun.2020

interpretação e compreensão dos dados, assegurar a validade do conteúdo produzido de forma fidedigna. (Minayo, 1994, 2012).

\section{RESULTADOS E DISCUSSÃO}

O conceito de pulsão, segundo Freud (1914/1916), pode ser entendido como possuidor de dois sentidos de transmissão de energia libidinal, sendo um deles o princípio norteador que motiva e direciona o sujeito a um objeto. E o segundo sentido, uma via contrária que recai sobre o sujeito na forma de um impacto. Uma característica importante da pulsão é que, diferente de outros estímulos externos, trata-se de uma força inata e constante, ou seja, algo que o tempo todo está instigando. Embora não empregue uma conotação qualitativa, existem dois tipos de pulsão denominados de vida (Eros), que serve para preservação, e morte (Thanatos), que pode servir para segregar a vida, uma energia de destruição. A ambivalência apresentada pela pulsão serve de ligação entre o anímico e o corpo físico (movimentos de ligação e anulação/desligamento).

A pulsão possui um sentido ambivalente que parece ser similar aos sentimentos vivenciados por pacientes diagnosticados com Micose Fungóide, uma vez que promove o aparecimento de movimentos opostos, mas não qualitativos, cujo único e essencial objetivo é sustentar o sujeito em um momento particularmente complexo.

O diagnóstico recebido pode despertar diversos sentimentos, independente de já haver ou não algum prejuízo à vida cotidiana. Estes sentimentos produzem alterações de rotina, impactos na autoestima, mudanças na aparência, nos relacionamentos, no trabalho, nos estudos e outros. Através das entrevistas foi possível investigar se as reações apresentadas indicariam a vivência de luto de forma antecipada. No entanto, isso só foi possível de ser constatado a partir da narrativa dos pacientes acerca de sua história clínica e dos aspectos que envolveram o diagnóstico do câncer. Catani (2015) afirma que “(...) [a] psicanálise, (...) visa analisar o significado do sofrimento para o sujeito, bem como o lugar que esse sofrimento ocupa, no intuito de descobrir a representação destes elementos, que irão constituí-los como sujeito" (p. 179).

Os relatos dos participantes evidenciaram essas distintas percepções relacionadas ao diagnóstico de MF. Através de análise compreensiva do conteúdo foi possível perceber variações, conforme as categorias estabelecidas: Categoria 1. Fases do 
[v.1, n.1] Jan./Jun.2020

Luto, Categoria 2. Mecanismos de Defesa e Categoria 3. Câncer como "sentença de morte".

Para a identificação dos participantes foram adotados nomes fictícios referentes à super heróis mutantes do X-Men, que também sofreram mutações em suas células. Fazendo uma alusão a personagens admirados por desenvolverem e/ou descobrirem habilidades, chamadas "super poderes", para lidar com as intempéries da vida, colaborando com o bem comum. Homenageamos esses heróis do cotidiano que buscam a melhor forma para enfrentar o "mal" da doença e suas consequências. São eles: Ororo, Charles, Mary e Raven, com idades entre 28 e 54 anos, grau de instrução técnico a superior, tempo de diagnóstico variando entre 2 e 10 anos. Cabe destacar que no momento da entrevista dois realizavam o tratamento e outros dois estavam no período de acompanhamento médico (Tabela 1). Suas falas foram preservadas tal qual proferidas no ato da entrevista, mantendo-se inclusive erros gramaticais e de concordância.

Tabela 1

Caracterização da Amostra.

\begin{tabular}{cccccc}
\hline Participante & Gênero & Idade & $\begin{array}{c}\text { Grau de } \\
\text { instrução }\end{array}$ & $\begin{array}{c}\text { Tempo de } \\
\text { Diagnóstico }\end{array}$ & $\begin{array}{c}\text { Está em } \\
\text { tratamento? }\end{array}$ \\
\hline Ororo & Feminino & 28 anos & Técnico & 2 anos & Não \\
Charles & Masculino & 54 anos & Superior & 10 anos & Não \\
Mary & Feminino & 34 anos & Superior & 6 anos & Sim \\
Raven & Feminino & 48 anos & Superior & 5 anos & Sim
\end{tabular}

\section{Categoria 1. Fases do Luto}

Categoria 1. Fases do Luto: Embora a Micose Fungóide seja uma doença crônica, é possível identificar o sentimento antecipatório despertado em cada participante. As expressões de luto puderam ser reconhecidas nas diferentes fases formuladas por Kubler-Ross. Às quais consideramos como subcategorias, sendo elas: negação, raiva, barganha, depressão e aceitação. 
[v.1, n.1] Jan./Jun.2020

Subcategoria 1.1. Fase da Negação. Na primeira fase abordada por Kubler-Ross, nomeada como Negação, há uma rejeição do problema. Esta fase pode ser observada apenas na afirmação de Mary que diz conviver pacificamente com a doença. Entretanto, detalha as diversas alterações sofridas em sua rotina de trabalho, estudo e família a partir do diagnóstico, implicando, inclusive, em sua mudança de estado. A participante destaca a necessidade de adaptação à nova realidade e busca minimizar seus impactos ao contar que já possuía outras doenças. Não foram identificadas falas dos demais participantes que pudessem ser classificadas nesta fase.

Mary: Então o que me marcou foi isso né, eu já tinha uma coisa e mais outra, então assim, talvez essa aceitação da doença, não bem aceitação, essa convivência "pacífica" tenha sido mais tranquila que pra uma pessoa que só teve a doença, por exemplo [referindo-se à MF], entendeu?! Ao meu ver.

Subcategoria 1.2. Fase da Raiva. A Raiva, classificada como Segunda Fase, pode compreender diversos sentimentos, demonstrando, de modo geral, certa indignação por ser o portador de tal doença. Conforme se pode observar, as falas a seguir evidenciam o sentimento identificado para as três mulheres participantes, bem como seus semblantes e entonação de voz, no ato da entrevista, também o fizeram.

Mary: Eu tenho escoliose e pé-torto e aí eu achava que o meu fardo estava completo né... tipo, aí quando veio a doença [referindo-se à MF] eu falei “caraca, mais uma? Não tá bom, não? Já deu né?!”

Raven: Em nenhum momento ela se abate, ela não deixa a doença passar. Eu falava pra ela, muitas vezes eu ficava aqui, chegava da fototerapia lá [participante cita o nome do Hospital neste momento], passava o dia inteiro aí, deitada. Eu tava de saco cheio. Não queria mimimi. E ela não, ela é forte, sabe?! Guerreira [ao falar sobre a sua colega com MF].

Ororo: Então assim, quando eu abandonei o tratamento, porque eu falei assim, meu, se não tem cura, por que que eu vou fazer? Abandonei. 
[v.1, n.1] Jan./Jun.2020

Literalmente, abandonei tudo, fiquei mais ou menos um ano sem fazer tratamento. Só que começou a surgir a necessidade, porque minha pele, ela, eu comecei a perder a minha pele. Começou a descascar, descascar, descascar.

Para Mary foi identificado o sentimento de revolta ao reagir a outro diagnóstico. Sabendo-se que, desde sua infância convivia com uma deficiência física que lhe gerava restrições no cotidiano e alguns conflitos de relacionamento, como bullying. No caso de Raven a Fase de Raiva é percebida pelo sentimento de "inveja" demonstrado ao elogiar a colega que, em sua percepção, lida bem com as adversidades, enquanto ela própria adotava um comportamento contrário. Na situação de Ororo que optou por abandonar o tratamento em dado momento, percebemos o ressentimento ao reconhecer os prejuízos causados por tal decisão.

Subcategoria 1.3. Fase da Barganha. A Barganha foi identificada no discurso de apenas uma participante, Ororo, a jovem de 28 anos de idade, diagnosticada há 2 anos, que evidenciava por diversos momentos sua participação ativa no âmbito religioso.

Ororo: Então, eu pensei, "olha, se o Senhor me prometeu que seria vida e vida com abundância, então eu creio, que não é uma vida de sofrimento”.

Em sua afirmação, a jovem parece cobrar de Deus o cumprimento de sua parte do "pacto", revelando a insatisfação diante da doença.

Subcategoria 1.4. Fase da Depressão. Ser diagnosticado com câncer, independente do quadro clínico e de seu prognóstico sempre implicará em algum sentimento semelhante ao recebimento de uma espécie de sentença de morte, como discutido anteriormente. No caso da MF, a dedicação exigida ao tratamento e sua manutenção influenciam na rotina da pessoa. Frente a possíveis estigmas e mudanças indesejadas é esperado que o paciente revele algum tipo de entristecimento. Lidar com as perdas potenciais pode indicar o reconhecimento da doença e, consequentemente, a tristeza despertada, abrangendo sentimentos de angústia e ansiedade.

Ororo: E no meu caso foi, foi pantrópico. Então assim é, na, no pêlo. Então assim, ele saia pra fora. Ficou uma coisa horrível. Eu sou mulher, 
[v.1, n.1] Jan./Jun.2020

imagina como eu me sentia?! Um lixo. Entendeu? Então assim, eu pensei em suicídio, só não fiz porque Deus foi maior na minha vida.

Charles: Nesses dois anos, eu vivi dois anos com a cabeça a mil por hora, sabe?! Pensando em tudo, medo de tudo, medo de morrer, medo de que minhas filhas poderiam ter, medo de não poder estar aqui e ver elas crescer, né?! E tal.

Raven: Essas coisas vão me limitar, pra, porque eu preciso a cada, pelo menos 3 meses, é... que os médicos me vejam, a [participante cita o nome da médica neste momento], o hemato. Então assim, é uma coisa que limita. Isso é uma coisa que me entristece.

Todos os participantes apresentaram falas classificadas nesta Fase, embora em proporções diferentes.

Subcategoria 1.5. Fase da Aceitação. Não se trata de felicidade, é provável que nesta fase a pessoa tenha conhecimento mais claro de suas limitações, sintomas e prognóstico. Uma postura mais próxima à aceitação foi observada no discurso de todos os participantes, destacamos a fala de dois deles:

Raven: [...] até falei pra [participante cita o nome da médica neste momento] dessa última vez, né, falei "doutora, eu cheguei à conclusão de que eu vou ter que viver com isso pra sempre, assim, uma ou outra placa no meu corpo eu sei que eu vou ter".

Charles: Hoje a minha conta é pela qualidade de vida. A minha ideia é a seguinte, morrer, todo mundo vai, a única diferença é que o meu passaporte está carimbado. Então eu não sei quando eu vou. Se todo mundo que tivesse saúde pensasse assim, talvez o pessoal fizesse mais coisas do que o normal.

Charles: Existe vida para quem tem câncer, existe vida e é boa! Dá para viver bem pra caramba, não precisa ter medo. É só ter coragem, ir pra frente, 
[v.1, n.1] Jan./Jun.2020

não se vitimizar e mandar bala. Claro, os nossos limites mudam, mas é só um fato a mais para nos acostumar.

Percebe-se que os relatos de Aceitação sugerem maior elaboração sobre o que se vivenciou e sobre o diagnóstico. Como se a pessoa tivesse se apropriado desta condição da qual não pôde abrir mão. No caso de Raven, que também apresenta o diagnóstico de vitiligo, destacamos o processo psicoterapêutico como provável facilitador.

De acordo com Rezende (2019), as fases do luto se apresentam de forma dual e cíclica, podendo haver repetição da vivência de determinado estágio sem que haja, necessariamente, o estacionamento em algum ou movimentos sequenciais típicos. Nos detivemos a expressar falas que exemplificam a forma de lidar com o luto, pois a partir do discurso de Ororo, Charles, Mary e Raven constatamos uma vivência peculiar dos estágios definidos por Kubler-Ross, não sendo possível indicar um padrão linear para a amostra.

\section{Categoria 2. Mecanismos de Defesa}

Categoria 2. Mecanismos de Defesa: Além de cada pessoa poder reconhecer-se dentro das etapas específicas acerca da vivência do luto, percebe-se que utiliza de manejos próprios para lidar com suas emoções, expectativas e vivências. Esses manejos para buscar enfrentamento mais adequado, se dão de forma inconsciente e são chamados de mecanismos de defesa se dividindo conforme suas características:

Subcategoria 2.1. Mecanismo de Deslocamento. Para Freud (1958/1970) o deslocamento se traduz em um movimento onde a satisfação pode ser limitada ou direcionada, trata-se de uma economia de energia, um investimento da libido suscetível de ser desligado de certas representações e deslizar por outros caminhos. O deslocamento é um mecanismo de defesa neurótico que permite ao indivíduo lidar com objetos estressores, com os quais ele evita contato ou não está totalmente preparado. No entanto, o deslocamento leva apenas à uma diminuição da tensão, por isso, não é uma defesa totalmente satisfatória. O indivíduo deixa de lado o objeto real e o que deveria ser elaborado, desenvolvendo hábitos ou afetos menos persecutórios e mais simples de serem trabalhados naquele momento. No recorte selecionado abaixo é possível perceber 
[v.1, n.1] Jan./Jun.2020

um movimento de deslocamento, onde Mary volta-se para os estudos como via de escape para lidar com o câncer.

Mary: Tô falando aqui que eu fico deslocada quando eu não tô estudando nem trabalhando. Quando é domingo, por exemplo, domingo eu estipulei que eu não vou fazer nada, assim, em relação ao resto da semana. E aí eu fico, parece que, é esquisito eu não tá na rotina.

No caso do câncer e toda a conotação estigmatizada que se apropria de seu significado, pode ser demasiado difícil de lidar diretamente, facilitando o acesso do sujeito a este tipo de defesa do ego. Vale ressaltar, nenhum mecanismo de defesa deve ser classificado em positivo ou negativo, eles representam exatamente aquilo que precisam ser e de certo modo, mesmo em indivíduos saudáveis, existe trânsito entre essas ferramentas de enfrentamento emocional da psique. Ou seja, eles possuem uma função reguladora e protetiva para o sujeito.

Subcategoria 2.2. Mecanismo de Altruísmo. Todos os entrevistados, direta ou indiretamente, manifestaram desejo de que suas falas fossem utilizadas para motivar outros pacientes. Para além disto, é interessante o próximo trecho de entrevista que demonstra forte envolvimento social entre uma das pacientes com seus colegas de tratamento.

Raven: Eu falava, “meu Deus do céu”, eu cheguei a comprar muito, eu, desempregada, eu comprava bastante creme [próprio para o tratamento] e levava prum monte de gente. Falava, "gente, tó. Tá aqui ó, usa”, sabe?! E então, a gente tem que tentar chegar em pessoas com menos condições.

O altruísmo é o antagônico do egoísmo, onde parte da energia libidinal investida em um determinado objeto volta-se para o próprio indivíduo com o intuito de satisfação do próprio ego (Laplanche, 1924/1991). O altruísmo é um mecanismo maduro que permite ao indivíduo reparar ou compensar algo. A pessoa lida com conflitos emocionais, dedicando-se a satisfazer as necessidades dos outros, em parte, como uma forma de satisfazer suas próprias necessidades. O altruísmo age parcialmente como 
[v.1, n.1] Jan./Jun.2020

reparador das consequências do próprio sujeito, gratificando necessidades sociais como meio de lidar com os seus próprios conflitos, canalizando sentimentos em ajuda social.

Subcategoria 2.3. Mecanismo de Intelectualização. O mecanismo de intelectualização também foi utilizado pelos entrevistados, o trecho abaixo evidencia uma tentativa de fuga da realidade dos fatos, tornando uma situação que deveria ser desconfortável em algo mais palatável e com explicação racional.

Charles: Quando eu chego [participante cita o nome do Hospital neste momento] o médico chama todo mundo e pede para verem esse cara, "vem ver esse cara. O que você tem? Você não parece ser uma pessoa que tem câncer", e eu acho isso muito importante.

A intelectualização não modifica a experiência de um determinado acontecimento, porém, trata a mesma de forma abstrata, separando os fatos dos sentimentos vivenciados, uma de suas finalidades é manter os afetos a distância e neutralizá-los (Laplanche, 1924/1991). A intelectualização é uma defesa de afetos e impulsos que mantém o sentimento na consciência, mas, o expressa de forma generalizada extraindo do objeto persecutório a sua qualidade e assim, minimizando a importância real do problema.

\section{Categoria 3. Câncer como "sentença de morte"}

Categoria 3. Câncer como "sentença de morte": No decorrer desta pesquisa destacamos o quanto o termo câncer carrega em si significantes relacionados diretamente à morte, podendo revelar sentimentos associados e expectativas do paciente quando recebe o diagnóstico.

De acordo com Kubler-Ross (1926/1998), "o simples fato de um paciente ser informado de que tem câncer já o conscientiza de sua possível morte, o câncer, para muitos, ainda é uma moléstia fatal" (p. 33). Não obstante, a evolução das possibilidades de tratamento e em determinados casos, inclusive de cura, pode também ser constatado entre os entrevistados desta pesquisa que revelam a sensação de sentença de morte na descoberta da doença. Ao receber o diagnóstico muitos sentimentos, fantasias e atitudes 
[v.1, n.1] Jan./Jun.2020

podem se precipitar diante do desafio de elaborar a informação recebida e buscar compreender o que pode ocorrer e o que se deseja a partir daquele momento.

Ororo: Que, na hora, eu tava assim, eu fiz assim ó: ufa, descobri o que eu tenho, de verdade. Descobri o que eu tenho, agora eu vou cuidar disso. Se eu tiver que morrer - porque é a primeira coisa que você pensa [risos], eu vou morrer logo. Se eu tiver que morrer, pelo menos o meu sofrimento acaba. Porque eu já tinha mesmo pensado em me matar, eu tinha.

Charles: A empresa me colocou na Caixa né, me encostou, aí eu voltei pra casa não tinha trabalho, aí começa né, você começa a achar que vai morrer... Câncer né, até você descobrir o que é.

Mary: Você fala em câncer e o quê que a pessoa pensa, sim você vai morrer logo, não é?!

Raven: Aí eu falei assim é... tudo parado na Avenida e eu fui procurar no Google o que era Micose Fungóide [risos]. Eu sozinha dentro do carro. Aí quando eu vi lá que era um câncer, raro, não sei o quê, nossa, eu comecei a chorar. Chorar tanto. Eu falei, "não é possível, não, eu não tenho isso, não tenho". [...] Porque aí todo mundo, no começo, "ai, é câncer, né, vai morrer [rindo] e não sei o quê". Mesmo eu também, falei "nossa, câncer!" Gente, vou morrer [rindo], em quanto tempo será, né?!

Verifica-se entre os entrevistados um forte abalo no primeiro contato com o termo câncer, em cada caso o estigma de morte foi preponderante ao menos na descoberta da doença. Ou seja, torna-se evidente o peso que este diagnóstico tem para cada um dos participantes. Ainda que essa vivência inicial não molde necessariamente suas vidas dali para frente, de alguma forma essa sensação e mal estar sempre ficarão vinculados aos instantes iniciais da notícia do diagnóstico.

\section{CONSIDERAÇÕES FINAIS}


[v.1, n.1] Jan./Jun.2020

O trabalho evidenciou limitações quanto ao número de produções científicas produzidas a respeito da MF, sobretudo no Brasil. De modo similar, a restrição pôde ser constatada também no acesso a possíveis participantes. Convém destacar que ao longo do processo a amostra sofreu redução devido à duas situações, quando uma participante necessitou deslocar-se para outra cidade em razão do tratamento médico impossibilitando na ocasião a colaboração na pesquisa. E a segunda, quando alguns participantes não aderiram à proposta, eventualmente por não se julgarem aptos para responderem ao estudo ou por um receio de se sentirem muito mobilizados pelas entrevistas.

O câncer afeta a vida do paciente de forma complexa promovendo sofrimento, inclusive pelo fato desta doença, muitas vezes, ser culturalmente interpretada como sinônimo de morte. Embora exista uma conotação negativa para este estigma, pôde-se supor um enfrentamento que permitiu reagir ao diagnóstico e não sucumbir em suas fantasias e afetos. Ressalta-se aqui, que diferente do que se imaginava inicialmente não foram reconhecidos quadros ou traços de melancolia entre os participantes. No entanto, constatamos quadro de entristecimento, congruentes com o momento vivido.

A partir das entrevistas realizadas nesta pesquisa foi possível observar diversos movimentos psíquicos que auxiliaram os participantes no confronto e ressignificação da doença. $\mathrm{Na}$ análise dos relatos constatou-se a vivência das cinco fases do luto (negação, raiva, barganha, depressão e aceitação) de maneira oscilante, o que pode estar relacionado às experiências subjetivas de cada pessoa. Ou seja, não houve um padrão diante de respostas apresentadas pelos pacientes. No entanto, constatou-se que a experiência do luto se deu de forma antecipatória, portanto, confirmando a hipótese inicial levantada pelos pesquisadores, isto é de que diante do diagnóstico de MF é mobilizada a vivência de um luto antecipado. É possível que a justificativa para tal fato seja o paciente tentando lidar com as suas fantasias e temores iniciais até conseguir localizar modos de elaboração de sua nova condição.

Foi verificada a mobilização de diversos mecanismos de defesa, entretanto, não se pôde classificar manejos específicos para os pacientes. Mecanismos de defesa são ferramentas inconscientes utilizadas pelo indivíduo para defender o ego de agressões intrínsecas e extrínsecas, deste modo, não foi possível estabelecer relação direta entre os 
[v.1, n.1] Jan./Jun.2020

pacientes de MF e determinados tipos de defesa. Isto porque estes variam de acordo com as características pessoais, a história de vida e as expectativas de cada um.

A mobilização emocional, a preparação pessoal e os recursos de cada participante para lidar com o sentimento de perda do futuro são sinais de vivência antecipada do luto. Todos os participantes demonstraram algum impacto diante do recebimento do diagnóstico e preocupação com o futuro a partir do mesmo. Ororo, Charles, Mary e Raven falam sobre como seus planos e sonhos ficaram comprometidos a partir das incertezas geradas pela descoberta da MF, antecipando sentimento de perdas e provocando mudanças significativas em seus projetos a curto, médio e longo prazo. Ao experimentar diferentes sentimentos e comportamentos foi possível caracterizar a vivência das fases do luto, bem como a necessidade inconsciente de recorrer a mecanismos que os protegessem do sofrimento. Mesmo com uma amostragem reduzida, na utilização destes recursos psíquicos constatamos a vivência do luto da morte em potencial. Diante destes achados clínicos de pesquisa, é possível pensar a partir dos resultados em formas de intervenção e cuidados terapêuticos para esta população, de modo que os pacientes tenham maior possibilidade de elaboração e construção de novos planos para o futuro depois de confirmado o diagnóstico de MF.

Por fim, sublinha-se que os resultados da pesquisa demonstram a importância dada aos aspectos culturais e imaginários a respeito do diagnóstico do câncer. Isto porque tal como já assinalado, a menção de sua palavra refere e faz o paciente associar a condição de morte e a uma finitude iminente, o que muitas vezes promove quadros e sentimentos de solidão e entristecimento que poderiam ser prevenidos a partir do fortalecimento de diálogos e articulações entre a medicina e a psicologia e psicanálise. Assim, julga-se que os profissionais em um trabalho de maior parceria e trocas clínicas possibilitaria identificar e cuidar dos sofrimentos advindos do diagnóstico. 
[v.1, n.1] Jan./Jun.2020

\section{REFERÊNCIAS}

Afonso, S. B. C., \& Minayo, M. C. S. (2013). Uma releitura da obra de Elisabeth Kubler-Ross. Ciência \& Saúde Coletiva, 18(9), 2729-2732.

Catani, J. (2015). Sofrimentos Psíquicos: As Lutas Científicas da Psicanálise e da Psiquiatria pela Nomeação, Diagnóstico e Tratamento. São Paulo, SP: Zagodoni.

Duarte, I., Buense, R., \& Aoki, S. (2006). Micose fungóide: estudo epidemiológico de 17 casos e avaliação da resposta terapêutica à PUVA. Anais Brasileiros de Dermatologia, 81(1), 40-45.

Dunker, C. Prefácio. In: Catani, J. (2015). Sofrimentos Psíquicos: As Lutas Científicas da Psicanálise e da Psiquiatria pela Nomeação, Diagnóstico e Tratamento. São Paulo, SP: Zagodoni, p. 13.

Freud, S. (1914-1916). Obras Psicológicas Completas (vol. XIV). Rio de Janeiro, RJ: Imago.

Freud, S. (1958). Dicionário de Termos de Psicanálise de Freud. Porto Alegre, RS: Editora Globo S. A. (Tradução de: Dictionary of Psychoanalisys, 1970).

Gaiewski, C. B. (2015). Perfil epidemiológico e avaliação histopatológica dos pacientes atendidos no ambulatório de Micose Fungóide do Serviço de Dermatologia da UFPR: Experiência do serviço (Dissertação). Universidade Federal do Paraná, Paraná.

Gil, A. C. (2010). Como elaborar projetos de pesquisa (5a ed.). São Paulo, SP: Atlas.

Kubler-Ross, E. (1998). Sobre a morte e o morrer: o que os doentes terminais têm para ensinar a médicos, enfermeiras, religiosos e aos seus próprios parentes (8a ed.) (P. Menezes, trad.). São Paulo, SP: Martins Fontes. (Trabalho original publicado em 1926)

Laplanche, J. (1991). Vocabulário de Psicanálise. São Paulo, SP: Martins Fontes. (Tradução de: Vocabulaire de la Psychanalyse, 1924).

Minayo, M. C. S. (1994). O desafio do conhecimento: Pesquisa Qualitativa em Saúde (3a ed.). São Paulo, SP: Hucitec-Abrasco.

Minayo, M. C. S. (2012). Análise qualitativa: teoria, passos e fidedignidade. Ciência Saúde Coletiva, 17(3), (paginação irregular).

Neto, J. O., \& Lisboa, C. S. M. (2017). Doenças associadas ao luto antecipatório: uma revisão da literatura. Psicologia Saúde \& Doenças, 18(2), 308-321.

Nunes, M. G., Pierro, A. P. S. M., Coutinho, F. V., Morais, J. C. O., Carneiro, S. C. S., \& Azulay, D. R. (2004). Linfoma cutâneo de células B: relato de caso. Anais Brasileiros de Dermatologia, 79(6), 715-720.

Rezende, F. (2019). Suicídio como desamparo humano: o fenômeno no olhar winnicottiano. São Paulo, SP: Fontenele Publicações.

Roudinesco, E., \& Plon, M (1998). Dicionário de Psicanálise. Rio de Janeiro, RJ: Zahar. (Tradução de: Dictionnaire de la Psychanalyse, 1944). 


\section{PSICOLOGIA}

[v.1, n.1] Jan./Jun.2020

ARTIGO DOI 10.33872/conversaspsico.v1n1.lutoantecipatorio

Sonoda, K. C. L. (2018). Luto e resiliência em vítimas da violência urbana no DF/Brasil. Psicologia Revista, 27(1), 57-82.

Susaki, T. T., Silva, M. J. P., \& Possari, J. F. (2006). Identificação das fases do processo de morrer pelos profissionais de Enfermagem. Acta Paulista de Enfermagem, 19(2), 144149.

Torres, W. T. (1994). O adolescente com câncer: o morrer. Temas em Psicologia, 2, 151-157.

Zimerman, D. E. (2008). Vocabulário Contemporâneo de Psicanálise. Porto Alegre, RS: Artmed. 